\title{
Impuestos y tecnología: una respuesta a la regresividad del IVA
}

\author{
Leonardo Hernández ${ }^{\mathrm{a}, \mathrm{b}}$ y Shirley Redroban ${ }^{\mathrm{b}}$ \\ a Pontificia Universidad Católica de Chile, Chile \\ b Centro Latinoamericano de Políticas Económicas y Sociales (CLAPES UC), \\ Chile
}

\begin{abstract}
Resumen: Con una tasa de 19\%, el impuesto al valor agregado (IVA) constituye una de las principales fuentes de ingreso del fisco chileno. Sin embargo, la regresividad de este impuesto constituye un problema no menor, por cuanto el IVA pagado representa una fracción más alta del ingreso disponible en los hogares de menores ingresos que en los hogares de ingresos altos. Sin pronunciarnos respecto a si se debe aumentar o disminuir la carga tributaria que soportan los consumidores, esto es, si la tasa promedio - y por ende la recaudacióndebe ser mayor o menor a la actual, en este documento se proponen dos métodos para disminuir la regresividad del IVA. En particular, mediante el uso de herramientas tecnológicas actuales, los contribuyentes podrían recibir un trato diferenciado de acuerdo a sus niveles de ingreso, gravándose con una tasa menor a los grupos de menores ingresos y con una tasa más alta a los grupos de ingresos más altos. El
\end{abstract}

Leonardo Hernández es ingeniero comercial y Magíster en Economía de la Pontificia Universidad Católica de Chile; MA en Economía y PhD en Business Economics de Columbia University, New York. Es director alterno del Centro Latinoamericano de Políticas Económicas y Sociales (CLAPES UC), Chile, y profesor de la Escuela de Administración, Pontificia Universidad Católica de Chile. Dirección: Av. Libertador Bernardo O'Higgins 440, piso 13, Santiago Centro, Santiago, Chile, CP 8331010. Email: fhernandezt@uc.cl.

Shirley Redroban es economista de la Pontificia Universidad Católica de Ecuador y Magíster en Economía de la Pontificia Universidad Católica de Chile. Es investigadora del Centro Latinoamericano de Políticas Económicas y Sociales (CLAPES UC), Chile. Dirección: Av. Libertador Bernardo O'Higgins 440, piso 13, Santiago Centro, Santiago, Chile, CP 8331010. Email: smredroban@uc.cl.

Agradecemos los valiosos comentarios de Hermann González y de dos árbitros anónimos que leyeron y comentaron una versión anterior de este artículo. 
incremento de tasa requerido para el segundo grupo es menos que proporcional, manteniéndose la recaudación y reduciéndose la regresividad del IVA. Las diferentes tasas se pueden aplicar al momento de la transacción (método ex dure) o vía una devolución de impuestos (método ex post). Para implementar estas soluciones se requiere de (1) certificados de exención tributaria vinculados a datos biométricos e integrados en tarjetas inteligentes de identificación, (2) regímenes de impuestos completamente digitaleslelectrónicos, (3) softwares certificados para la determinación de los impuestos y (4) transferencias digitales directas (cuenta RUT universal).

PalABRAS CLAVE: IVA, impuestos, regresividad, tecnología, modernización

RECIBIDO: abril 2021 / ACEPTADO: diciembre 2021

\section{Taxes and Technology: An Answer to Vat Regressivity}

ABSTRACT: With a rate of $19 \%$, the value added tax (VAT) is one of the main sources of revenue for the Chilean government. However, the regressivity of this tax is not a minor problem. The tax paid as a share of disposable income is higher in low-income households than in high-income households. Without taking position on whether the tax burden borne by consumers (households) should be increased or decreased, that is, whether the average rate - and therefore, total revenue collection - should be higher or lower than it is at present, this paper proposes two methods to reduce VAT regressivity. In particular, through the use of available technological tools taxpayers could receive different treatment according to their income levels, with a lower rate being applied to low-income groups and a higher rate to high-income groups. The increase in the rate to the high-income group is less than proportional. This reduces the regressivity of the VAT while keeping total tax revenue constant. This could be done during the purchase of a good or service (ex dure method), or after a short period (ex post method) through a tax reimbursement. The requirements to implement these solutions are: (1) tax exemption certificates linked to biometric data and integrated into smart ID cards; (2) fully digital tax regimes; (3) certified tax assessment software; and (4) direct digital transfers (RUT account).

KEYWORDS: VAT, taxes, regressivity, technology, modernization

ReCeived: April 2021 / Accepted: December 2021 
a recaudación tributaria constituye una de las principales fuentes de ingreso de los Estados, con la que los gobiernos pueden financiar parte de sus gastos. A través del cobro de impuestos, el Estado asegura recursos para financiar estrategias de crecimiento y desarrollo, además de programas sociales (Bird y Zolt 2008). Uno de los impuestos más ampliamente usado es el Impuesto al Valor Agregado o IVA, que, a diferencia de otros impuestos al consumo, grava el valor que se añade a un bien o servicio en cada etapa de su producción y/o comercialización (SII 2016).

En la actualidad, más de 160 países han adoptado el IVA como parte de sus sistemas impositivos (IMF 2018). En Chile, la tasa que se aplica por este concepto es de 19\%, cifra que se ubica tres décimas por debajo de la tasa promedio de los países miembros de la OECD (19,3\%). Pese a esto, la recaudación por concepto del IVA, como porcentaje de la recaudación total, es del 41,3\% en Chile, en comparación con el 20,2\% de la recaudación promedio en los países de la OECD, ${ }^{1}$ lo que muestra la importancia del impuesto en los ingresos del fisco chileno.

El uso generalizado del IVA a nivel mundial se debe a que es un impuesto de fácil aplicación, con menos distorsiones y más difícil de evadir que otros, como los impuestos al ingreso (James 2015). Muestra de ello son las estimaciones del exdirector del Servicio de Impuestos Internos, Michel Jorratt (2020), que indican que en 2018 la evasión del IVA alcanzó un $2,2 \%$ del PIB, en comparación con el 4,5\% del Impuesto a la Renta de Primera Categoría. ${ }^{2}$ Sin embargo, su desventaja es su gran regresividad. Como el impuesto al valor agregado ignora la capacidad de pago de un individuo, la carga tributaria como proporción del ingreso resulta más alta para las personas con menores ingresos y ahorro, y decrece a medida que el ingreso y el ahorro aumentan (Tax Policy Center 2018).

En esta línea, distintas medidas han sido sugeridas y/o adoptadas para aliviar la regresividad del impuesto. Algunos sistemas tributarios han partido por identificar aquellos bienes y servicios que tienen un mayor peso en la canasta de consumo de los hogares más pobres y aquellos que pueden considerarse de interés social. Una vez identificados estos

\footnotetext{
1 OECD (2019), Revenue Statistics 2019. Disponible en: https://www.oecd.org/economy/ revenue-statistics-2522770x.htm [2 de diciembre 2021].

2 De eliminarse la evasión del IVA, la recaudación del impuesto podría ascender al 10,4\% del PIB, cifra que se encuentra 2,2 puntos porcentuales por encima del $8,2 \%$ recaudado en el último año (ver cifra más adelante). Las cifras calculadas por Jorratt (2020) son consistentes con las estimaciones del SII (2018), que sugieren que en 2018 la tasa de evasión del IVA alcanzó el 21,3\%.
} 
bienes y servicios se propone ocupar tasas distintas según los distintos tipos de bienes y servicios, excluir algunos de estos bienes de la base del impuesto o una combinación de ambas herramientas.

Sin embargo, aunque desde el punto de vista de política fiscal/tributaria esta solución es de fácil ejecución, el problema es que este mecanismo no permite distinguir entre distintos tipos de contribuyentes, por lo que no se logra una buena focalización y, por lo tanto, no se está seguro de beneficiar solamente a las personas de menores ingresos (Barreix, Bes y Roca 2012). ${ }^{3}$

Alternativamente, otros sistemas han intentado solucionar la regresividad del IVA a través de un mayor gasto social. Precisamente, algunos autores señalan que la regresividad del impuesto queda solucionada a través del efecto distributivo del gasto social, el cual beneficia en su mayoría a los hogares de menores ingresos (Engel, Galetovic y Raddatz 1997). El problema, en este caso, es que los beneficios de los programas sociales pueden no guardar relación con el IVA pagado ${ }^{4}$ (Bennet 2020), por lo que cualquier reforma que busque mejorar el efecto redistributivo del IVA debería enfocarse en la aplicación del tributo o en la devolución directa del impuesto.

En este contexto, la presente investigación expone dos métodos que, mediante el uso de tecnología de punta, pueden reducir la regresividad del IVA. La primera alternativa corresponde al uso de tecnología ex dure o durante el pago del tributo. En este caso, los contribuyentes podrían ser sujetos de un trato diferenciado (en la tasa del impuesto aplicada) en el momento de la compra, de acuerdo a sus niveles de ingresos. Para esto son necesarios tres desarrollos tecnológicos: (1) certificados de exención tributaria (parcial o total) vinculados a datos biométricos e integrados en tarjetas inteligentes de identificación; (2) regímenes de impuestos digitaleslelectrónicos, esto es, emisión de facturas y boletas electrónicas en línea; y (3) softwares certificados para la determinación de los impuestos (Ainsworth 2006a).

Una segunda alternativa contempla una solución ex post al pago del impuesto. Específicamente se propone una devolución (parcial o

\footnotetext{
${ }^{3}$ Adicionalmente, esta solución distorsiona los precios relativos, alterando la asignación de recursos en la economía, por lo que creemos es una solución inferior a las discutidas en este trabajo.

${ }^{4}$ En otras palabras, los beneficiarios de los programas no necesariamente valoran los beneficios recibidos de acuerdo al IVA pagado - pueden recibir un servicio o bien desde el Estado que valoran menos que el impuesto pagado.
} 
total) del IVA pagado a un grupo específico de beneficiarios (hogares de menores ingresos) después de un plazo determinado. Para ello, tres avances tecnológicos son indispensables. Similar al método ex dure, se requiere de la digitalización del impuesto y de softwares certificados, pero, además, se requiere de un canal de pagos o transferencias digitales de manera que la devolución del IVA sea directa a una cuenta asociada al beneficiario (cuenta RUT). ${ }^{5}$

La presente investigación constituye un aporte para la discusión sobre una posible reforma tributaria en la actual coyuntura. Considerando que en 2020, a causa de la pandemia del Covid-19, la economía se contrajo en un $5,8 \%$, el gasto del gobierno central aumentó en un 10,4\% real respecto de la ejecución de 2019, el endeudamiento alcanzó el 32,5\% del PIB, y que 2021 requirió de enormes apoyos a las familias en la forma de transferencias, deteriorando aún más la posición financiera del gobierno por el uso de los fondos soberanos (a pesar de la recuperación económica), es evidente que el Estado requerirá de mayores ingresos en el futuro, si no permanentemente, a lo menos por un número acotado y no menor de años.

Si bien existen otras posibilidades para responder a este desafío (reducción en la evasión y la elusión; eliminación de exenciones tributarias como el impuesto al diésel; reducción de gastos en programas fiscales mal evaluados; y aumento en la base del impuesto a la renta de las personas, reduciendo el número de tramos exentos), el cambio en la tasa de gravamen del IVA es una opción a la que con frecuencia recurren distintos agentes económicos.

De hecho, en el contexto de la reforma de pensiones actualmente en discusión parlamentaria, la que significaría un mayor gasto fiscal de manera permanente, algunas autoridades —entre ellas el exministro de Hacienda Ignacio Briones - han sugerido aumentar la tasa del IVA entre uno y dos puntos porcentuales, ${ }^{6}$ mientras que algunos diputados han

\footnotetext{
${ }^{5}$ Otros requisitos no asociados con la tecnología son discutidos en secciones posteriores.

${ }^{6}$ Véase 'Gobierno evalúa elevar la cotización adicional para paliar impacto de retiro de fondos', El Mercurio, 31 de diciembre 2020. Disponible en: https://digital.elmercurio. com/2020/12/31/B/BA3TABI4\#zoom=page-width [02 de diciembre 2021]. También 'Reforma de pensiones entra en semana clave y oposición se abre a subir tasa de cotización al 18\%', Diario Financiero, 5 de enero 2021. Disponible en https://www.df.cl/noticias/ economia-y-politica/laboral-personas/reforma-de-pensiones-entra-en-semana-clave-yoposicion-se-abre-a-subir/2021-01-04/204035.html [2 de diciembre 2021].
} 
sugerido la devolución del impuesto a algunos grupos de modo de compensar su regresividad. ${ }^{7}$ Este documento entrega dos opciones capaces de disminuir la regresividad del IVA, las que debiesen estar presentes en la discusión sobre una posible reforma a este impuesto.

El documento se ordena de la siguiente manera. En la sección 1 se describe el impuesto al valor agregado en Chile, haciendo énfasis en su importancia dentro de los ingresos fiscales y en su impacto en el ingreso de los hogares. La sección 2 presenta de forma detallada dos métodos que, basados en desarrollos tecnológicos actuales, son capaces de lograr un impuesto menos regresivo. La sección 3 adelanta algunas conclusiones.

\section{EI IVA en Chile}

El Impuesto al Valor Agregado (IVA) es un impuesto al consumo (impuesto indirecto), que opera gravando el valor que se agrega a un bien o servicio a lo largo de toda la cadena de producción y comercialización. En Chile, la tasa de gravamen por este concepto es de 19\%, tres décimas porcentuales menor a la tasa promedio de los países miembros de la OECD $(19,3 \%)$ y cuatro puntos porcentuales mayor a la tasa de gravamen promedio de América Latina (15\%). De hecho, Chile posee la tercera tasa de IVA más alta de Latinoamérica, situándose únicamente por debajo de Uruguay (22\%) y Argentina (21\%) (Figura 1).

Este impuesto constituye una de las principales fuentes de financiamiento para el fisco chileno. De los $\$ 34,6$ billones $^{8}$ que se recaudaron en 2019 por concepto de impuestos (17,4\% del PIB), $\$ 16,3$ billones $(47,1 \%)$ correspondieron a la recaudación del IVA, $\$ 14,2$ billones (41\%) al Impuesto a la Renta ${ }^{9}$ y el monto restante a otros tributos como los impuestos a productos especíicos (por ejemplo, tabacos y combustibles) o a los actos jurídicos (timbres y estampillas) (Dipres 2020). Asimismo, durante

\footnotetext{
7 Véase 'Diputados UDI solicitarán al Gobierno que a personas más vulnerables se les devuelva el IVA', El Mercurio, 14 de diciembre 2020. Disponible en https://digital.elmercurio. com/2020/12/14/B/0O3T3K7P\#zoom=page-width [2 de diciembre 2021].

81 billón = 1 millón de millones. Las cifras se refieren al gobierno central; no incluyen impuestos locales ni seguridad social.

${ }^{9}$ De acuerdo a lo informado por Tesorería, en 2018 y 2019 la recaudación por el Impuesto a la Renta superó a la del IVA (https://www.tgr.cl/wp-content/uploads/2020/06/Cuenta_Publica_2019.pdf). Sin embargo, los datos del SIl y de la Dipres coinciden en que la recaudación por IVA ha superado sostenidamente a la de Impuesto a la Renta en dicho período.
} 
los últimos diez años el monto recaudado anualmente por concepto de IVA representa el $8,2 \%$ del PIB, cifra que está por encima de lo generado a raíz del impuesto a la renta $(7,0 \%)$ y de otros impuestos (2,2\%) (Figura 2 ).

Figura 1. TASAS DE GRAVAMEN POR CONCEPTO DEL IVA

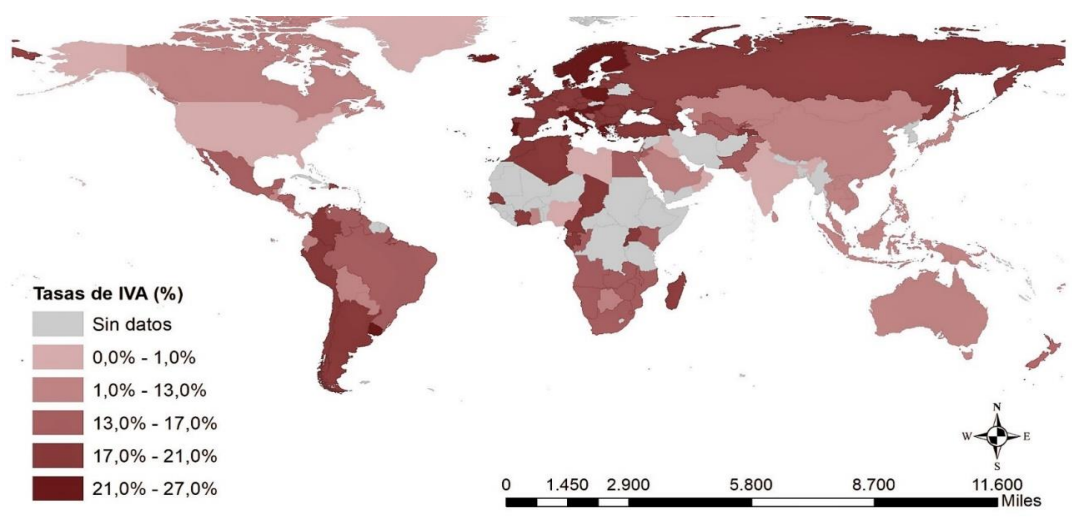

Fuente: Elaboración propia a partir de información de Worldwide Tax Sumaries (2019).

Figura 2. RECAUDACIÓN TRIBUTARIA COMO PORCENTAJE DEL PIB (2010-2020)

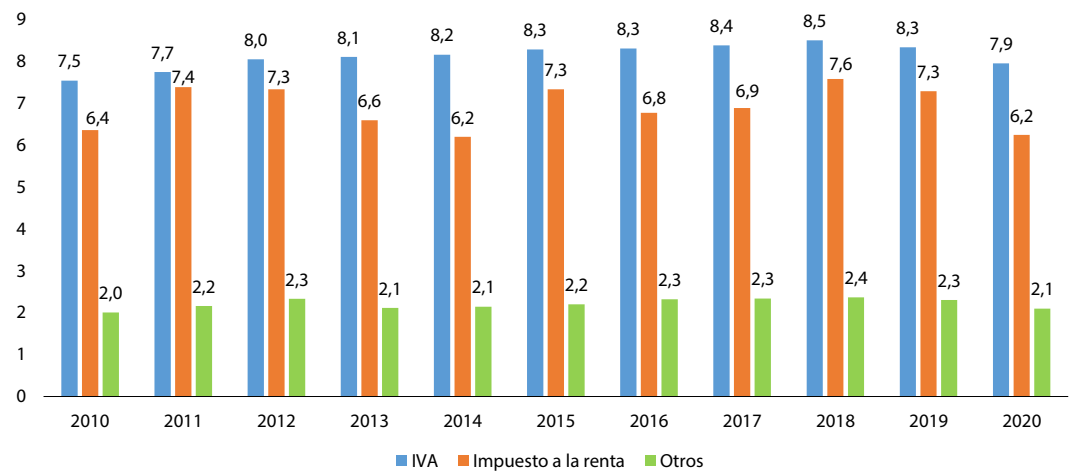

Nota: 'Otros' incluye impuestos a productos específicos, impuestos a los actos jurídicos, impuestos al comercio exterior e impuestos varios (herencias, patentes, etc.).

Fuente: Elaboración propia a partir de información del Servicio de Impuestos Internos. 
Al analizar solo los ingresos recaudados por impuestos se evidencia que, aunque más del $80 \%$ de los ingresos tributarios corresponden a ingresos por impuesto a la renta e IVA (Figura 3), este último constituye la principal fuente de ingresos fiscales. De hecho, la recaudación promedio producto del IVA en los últimos diez años asciende al $47,8 \%$ de los ingresos fiscales tributarios, cifra 7,2 puntos porcentuales por encima de la recaudación promedio producto del impuesto a la renta que se sitúa en el $40,6 \%$.

El porcentaje de recaudación llega a ser incluso el doble de la recaudación del impuesto en otros países. Por ejemplo, de acuerdo a las últimas cifras de la OECD, en 2017 la recaudación promedio a causa del IVA como porcentaje de los ingresos tributarios se ubicó en $27,8 \%$ en Latinoamérica y en los países de la OECD alcanzó el 20,2\%. Es claro, entonces, el importante rol de este impuesto a nivel fiscal en el país.

Figura 3. RECAUDACIÓN TRIBUTARIA SEGÚN TIPO DE IMPUESTO 2010-2020 (VALORES COMO PORCENTAJE)

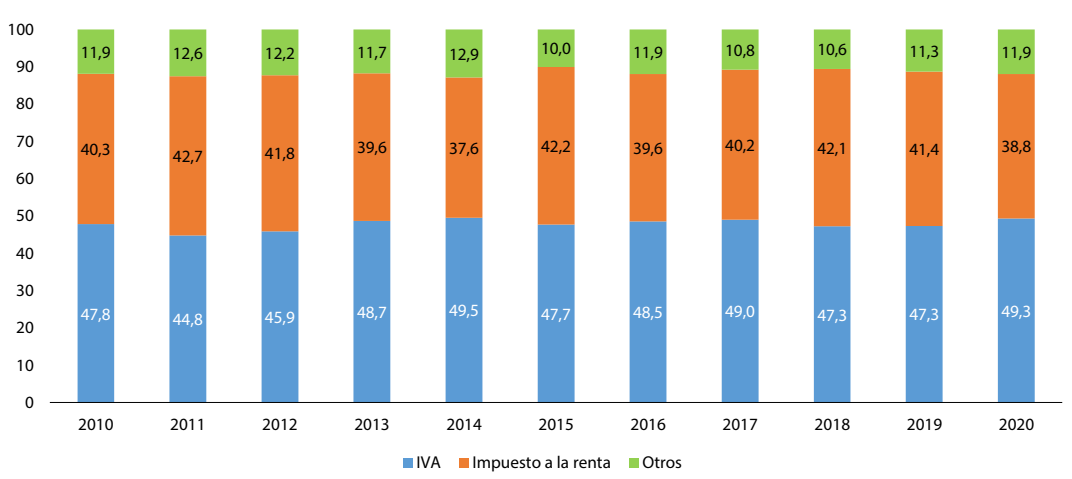

Nota: 'Otros' incluye impuestos a productos específicos, impuestos a los actos jurídicos, impuestos al comercio exterior e impuestos varios (herencias, patentes, etc.).

Fuente: Elaboración propia a partir de datos del Servicio de Impuestos Internos.

Pese a su rol predominante en las arcas fiscales es importante analizar el efecto del impuesto en el ingreso de los hogares. Para ello utilizamos la VIII Encuesta de Presupuestos Familiares (EPF) (INE 2018) correspondiente al período julio de 2016 a junio de 2017. La EPF es una encuesta socioeconómica que se aplica cada cinco años a una muestra representativa de hogares por parte del Instituto Nacional de Estadísticas (INE). Su propósito es recopilar información sobre los gastos en los que 
estos incurren y los ingresos que perciben en un período determinado. Para ello, la EPF recopila dicha información durante doces meses consecutivos con el fin de incorporar cualquier variación estacional. Así, a través de la información recogida sobre el ingreso y gasto declarados ${ }^{10} \mathrm{de}$ los hogares, se procede a analizar la regresividad del impuesto.

Figura 4. INGRESO DISPONIBLE Y GASTO PROMEDIO MENSUAL SEGÚN DECIL DE INGRESO

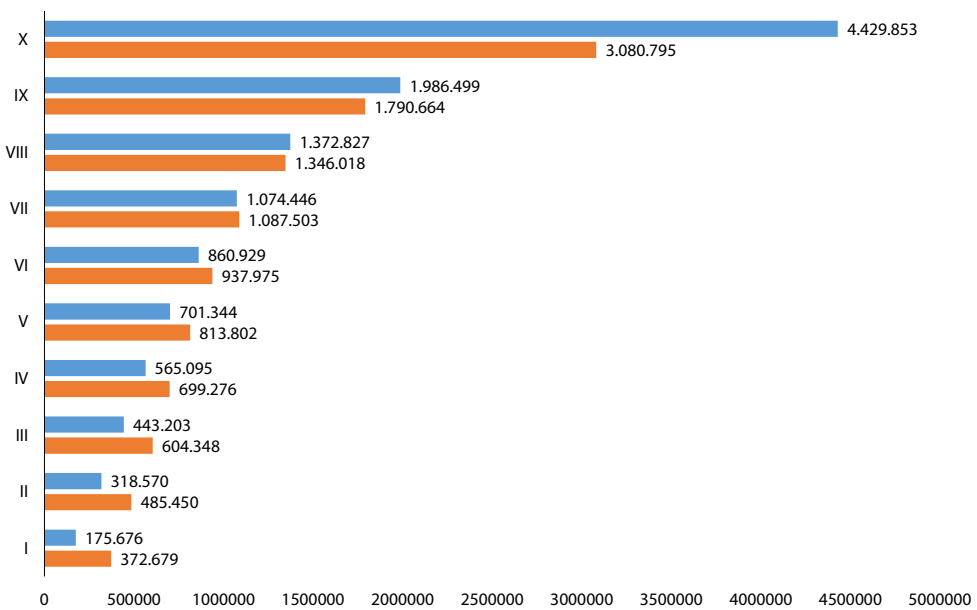

Fuente: Elaboración propia a partir de VIII Encuesta de Presupuestos Familiares (EPF) (INE 2018).

Como punto de partida se clasifica a los hogares según decil de ingreso disponible del hogar, observándose grandes disparidades en el nivel de ingreso promedio. Como muestra de ello, mientras en el decil I el ingreso disponible promedio mensual de los hogares asciende a aproximadamente $\$ 176.000$, en el decil $X$ el ingreso promedio mensual alcanza a $\$ 4.429 .853$ (Figura 4); es decir, el 10\% de los hogares de mayores ingresos tiene un ingreso disponible promedio más de 25 veces el ingreso promedio de los hogares más pobres. Sin embargo, las diferencias observadas entre deciles - aunque aún muy significativas - son menores con

\footnotetext{
${ }^{10}$ En la VIII EPF, el ingreso corresponde al ingreso disponible (ID) del hogar, que equivale a la suma de las fuentes de ingreso que el hogar percibió durante el mes anterior a la aplicación a la encuesta, más las transferencias corrientes netas (ID = ingresos del trabajo, más ingresos de la propiedad, más transferencias corrientes recibidas, como pensiones o beneficios de asistencia social en efectivo derivados del gobierno, menos impuesto a la renta, menos contribuciones por seguridad social, menos transferencias en efectivo pagados a otros hogares y menos transferencias en efectivo pagadas a instituciones sin fines de lucro). Con respecto al gasto, contabiliza los gastos realizados a través de transacciones en el mercado y no considera ninguna transferencia social en su contabilización (educación, asistencia sanitaria, entre otras).
} 
respecto al gasto del hogar: el gasto promedio del decil más rico es 8,3 veces el del decil más pobre. ${ }^{11}$

La estructura del gasto también difiere entre deciles. En la Figura 5 se observa que la proporción del gasto que se destina a alimentos y bebidas no alcohólicas y a alojamiento, agua, electricidad, gas y otros combustibles tiende a disminuir a medida que aumenta el nivel de ingreso disponible de los hogares - a modo de ejemplo, la proporción del gasto que los deciles I y II destinan al consumo de alimentos y bebidas no alcohólicas (27\%) es 2,4 veces la del decil X (11\%).

Como contrapartida, la proporción del gasto que el decil $\mathrm{X}$ destina a las divisiones muebles, artículos para el hogar y para la conservación ordinaria del hogar, recreación y cultura, restaurantes y hoteles, y bienes y servicios diversos es más del doble de la proporción del gasto destinada en el decil I. Como ejemplo, mientras el decil I destina el 3,9\% de su ingreso disponible en este gasto, el decil $X$ destina el 9,3\% en la división muebles, artículos para el hogar y para la conservación ordinaria del hogar. Pese a lo anterior, existen divisiones en las que la proporción del gasto que se destina a su consumo es similar (o menos disímil) entre los distintos grupos. Estas divisiones corresponden a salud y comunicaciones y en menor grado a bebidas alcohólicas, tabaco y estupefacientes, y prendas de vestir y calzado.

Por otro lado, si se analiza únicamente el gasto afecto a IVA ${ }^{12}$ (gasto en bienes y servicios que están afectos al IVA), se observa que la desigualdad entre deciles se mantiene respecto de lo observado en la Figura 4 -el gasto afecto a IVA del decil más rico es 8,3 veces el del decil más pobre (Figura 6).

\footnotetext{
${ }^{11}$ Tal y como lo muestra la Figura 4, en los primeros siete deciles el gasto promedio es superior al ingreso promedio de los hogares. Este resultado es similar a lo observado en las Encuestas de Presupuestos Familiares anteriores, correspondientes a los años 1996-1997, 2006-2007 y 2011-2012 (Irarrázaval 2018). Cabe mencionar que la literatura no es clara en señalar la manera en que dicha brecha entre gastos e ingresos es solventada (parte podría explicarse por endeudamiento).

12 Para el cálculo del gasto afecto a IVA se consideraron las exenciones más importantes al impuesto establecidas en el Decreto Ley $N^{\circ} 825$ sobre Impuestos a las Ventas y Servicios; estas corresponden a transporte, educación, salud y alojamiento (alquiler de bienes inmuebles). No se consideran servicios financieros, seguros y otras partidas menores de gasto también exentas. Para mayor información revisar Anexo 1.
} 
Figura 5. ESTRUCTURA DEL GASTO SEGÚN DECIL DE INGRESO DISPONIBLE DEL HOGAR
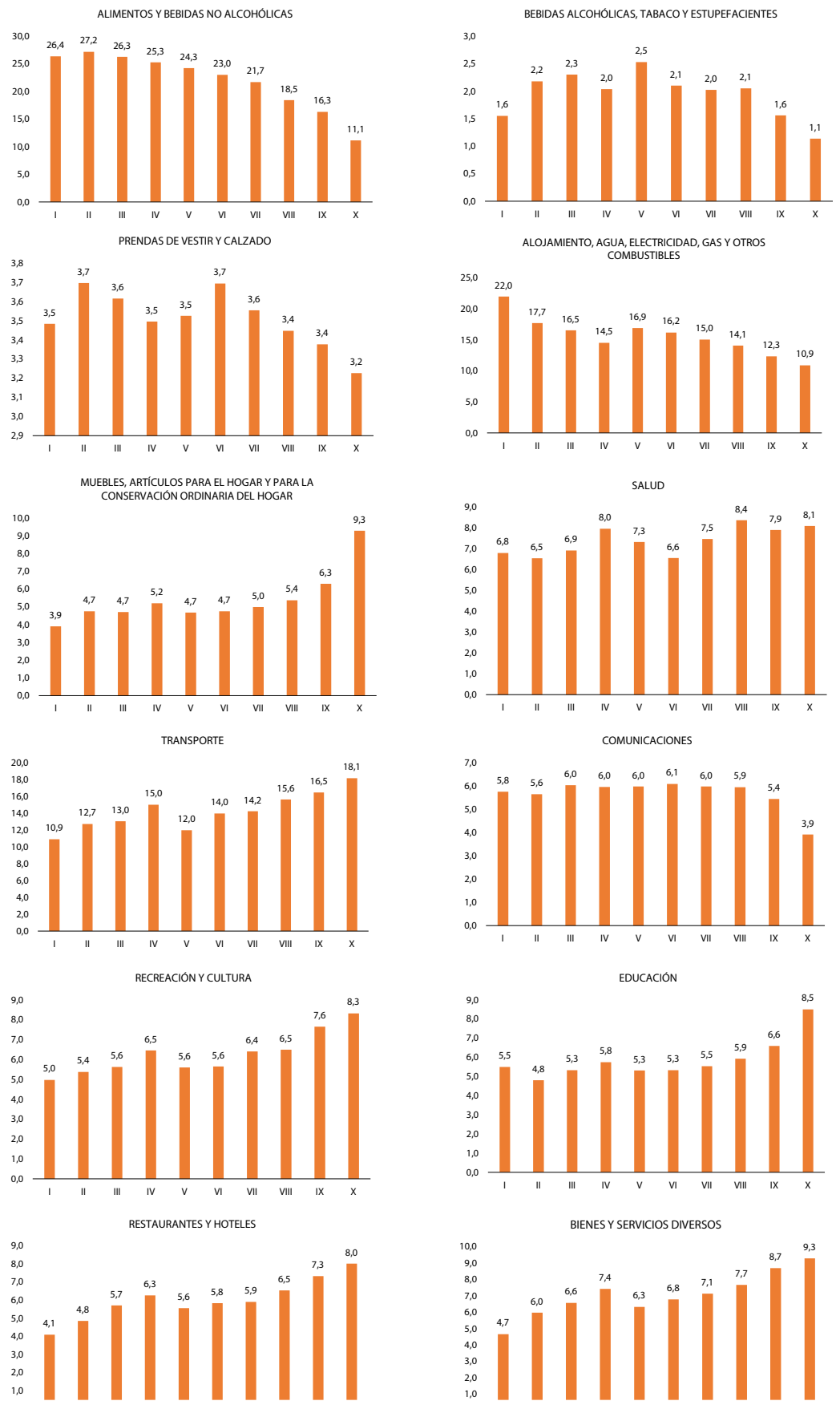

Fuente: Elaboración propia a partir de VIII Encuesta de Presupuestos Familiares (EPF) (INE 2018). 
Figura 6. INGRESO GASTO EN IVA COMO PROPORCIÓN DEL INGRESO DISPONIBLE (VALORES PROMEDIO MENSUAL POR DECIL*)

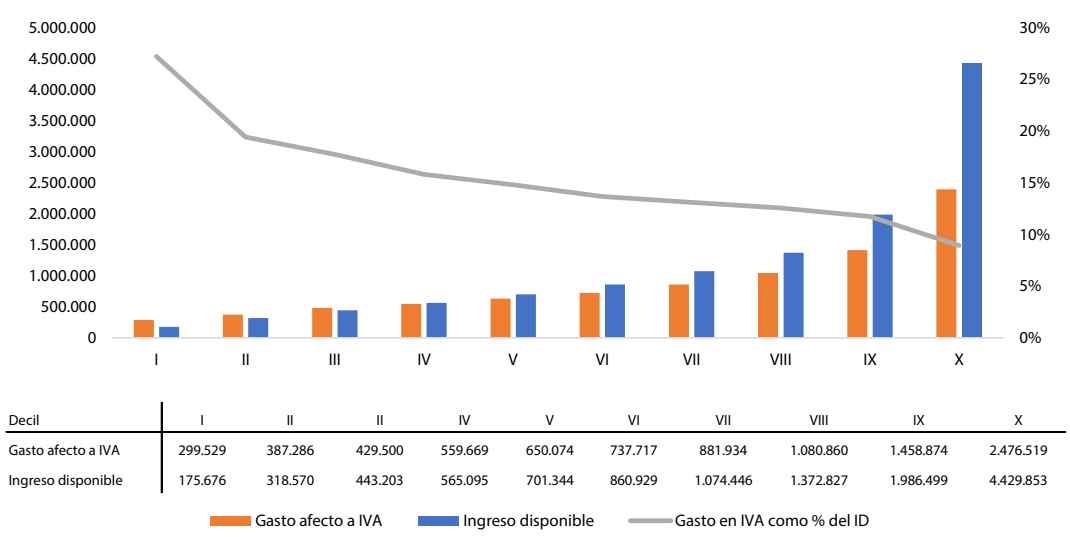

* Los montos corresponden a valores promedio mensuales por decil. Para el cálculo se considera el gasto por hogar en bienes y servicios afectos al IVA de manera de obtener el valor correspondiente al pago del impuesto.

Fuente: Elaboración propia a partir de VIII Encuesta de Presupuestos Familiares (EPF) (INE 2018).

Asimismo, al medir el gasto en IVA ${ }^{13}$ como proporción del ingreso disponible declarado promedio según decil, se observan amplias diferencias entre los hogares de menores y mayores ingresos. Así, mientras en los hogares pertenecientes al decil I de ingresos el $27,2 \%$ de su ingreso disponible se destina al pago de este impuesto, en los hogares del decil $X$ este uso alcanza a apenas el $8,9 \%$ del ingreso disponible; es decir, algo menos de un tercio de lo que destina el $10 \%$ más pobre. En resumen, el IVA representa una carga tributaria mayor para los hogares de menores ingresos.

Frente a esto, una alternativa al impuesto capaz de disminuir su regresividad sería el establecimiento de tasas de gravamen diferenciadas según el nivel de ingreso de los individuos.

Suponiendo que esto es posible y manteniendo fija la recaudación actual bajo la tasa única del 19\% (statu quo), la que asciende a los

\footnotetext{
${ }^{13}$ Corresponde al monto que se paga por concepto del impuesto (Gasto en IVA $=19 \%{ }^{*}$ gasto afecto a IVA $/(1+19 \%))$.
} 
$\$ 10.018 .875$ millones, $^{14}$ en la Tabla 1 se presentan tres alternativas de tasas diferenciadas según nivel de ingresos, en las que se reduce la tasa del impuesto a los cuatro primeros deciles y se aumenta la de los deciles de mayor ingreso.

La primera alternativa reduce la tasa del IVA en tres puntos porcentuales (pp) para los cuatro primeros deciles y mantiene la tasa actual (19\%) en los deciles V y VI. En este caso se estima que el impuesto debería ascender en 0,9 puntos porcentuales en los cuatro deciles de mayor ingreso para mantener el nivel de recaudación actual -0,3 pp de aumento por cada pp de reducción a los deciles de menor ingreso.

En la segunda alternativa se reduce la tasa del impuesto en seis puntos porcentuales para los hogares de los primeros cuatro deciles y se mantiene la tasa de $19 \%$ en los deciles $V$ y VI. En este caso se estima que la tasa aplicable a los deciles de mayores ingresos (del decil VII al decil X) debería aumentar en 1,8 puntos porcentuales para mantener el mismo nivel de recaudación.

La tercera y última alternativa consiste en una opción más focalizada que las anteriores. En este caso se reduce la tasa del IVA en ocho puntos porcentuales para los deciles I y II, y en cuatro puntos para los deciles III y IV. Además, se mantiene la tasa de 19\% en los deciles V y VI. En este caso, para mantener el nivel de recaudación actual la tasa de gravamen debería aumentarse en un punto porcentual para los deciles VII y VIII, y en dos puntos porcentuales para los deciles IX y X.

Los resultados presentados (Tabla 1) indican que por cada punto porcentual en que la tasa de gravamen del IVA es reducida para los deciles de menores ingresos, la tasa del impuesto en los grupos de mayores ingresos debería aumentarse menos que proporcionalmente para compensar la pérdida en recaudación -en particular, en 0,3 puntos porcentuales cuando el aumento es igual para los cuatro deciles más ricos

\footnotetext{
${ }^{14}$ El valor se encuentra por debajo de lo reportado por la Dipres, que indica que la recaudación en 2017 fue de $\$ 15.069 .540$ millones, es decir, existe una diferencia aproximada del 33\%. La diferencia entre ambos valores puede ser explicada por el subregistro en el número de hogares o por el subreporte en el consumo de los hogares al momento de la encuesta. Adicionalmente, algunos insumos productivos están afectos a IVA, montos que no son reembolsados en su totalidad a las empresas (combustibles, construcción, etc.). Lo mismo pasa con el IVA pagado por instituciones sin fines de lucro. Estos montos no quedan reflejados en la canasta de consumo de los hogares. Por lo tanto, las estimaciones obtenidas a partir del análisis deben ser tomadas como un límite inferior.
} 
(alternativas 1 y 2) y en 0,125 y 0,25 puntos para los deciles VII-VIII y IX-X, respectivamente, cuando el aumento es escalonado (alternativa 3 ). ${ }^{15}$

Tabla 1. RECAUDACIÓN ANUAL SEGÚN DECIL DE INGRESO Y TASA DE GRAVAMEN (MILES DE MILLONES)

\begin{tabular}{lccccccccccc}
\hline Decil & I & II & III & IV & V & VI & VII & VIII & IX & X & Total \\
\hline Statu quo & $19,0 \%$ & $19,0 \%$ & $19,0 \%$ & $19,0 \%$ & $19,0 \%$ & $19,0 \%$ & $19,0 \%$ & $19,0 \%$ & $19,0 \%$ & $19,0 \%$ & \\
Recaudación & 332,5 & 429,9 & 546,7 & 621,3 & 721,7 & 819,0 & 979,1 & 1199,9 & 1619,5 & 2749,3 & 10.019 \\
Alternativa 1 & $16,0 \%$ & $16,0 \%$ & $16,0 \%$ & $16,0 \%$ & $19,0 \%$ & $19,0 \%$ & $19,9 \%$ & $19,9 \%$ & $19,9 \%$ & $19,9 \%$ & \\
Recaudación A1 & 280,0 & 362,1 & 460,4 & 523,2 & 721,7 & 819,0 & 1024,6 & 1255,8 & 1694,9 & 2877,2 & 10.019 \\
Alternativa 2 & $13,0 \%$ & $13,0 \%$ & $13,0 \%$ & $13,0 \%$ & $19,0 \%$ & $19,0 \%$ & $20,8 \%$ & $20,8 \%$ & $20,8 \%$ & $20,8 \%$ & \\
Recaudación A2 & 227,5 & 294,2 & 374,1 & 425,1 & 721,7 & 819,0 & 1070,2 & 1311,6 & 1770,3 & 3005,2 & 10.019 \\
Alternativa 3 & $11,0 \%$ & $11,0 \%$ & $15,0 \%$ & $15,0 \%$ & $19,0 \%$ & $19,0 \%$ & $20,0 \%$ & $20,0 \%$ & $21,0 \%$ & $21,0 \%$ & \\
Recaudación A3 & 192,5 & 248,9 & 431,6 & 490,5 & 721,7 & 819,0 & 1030,6 & 1263,0 & 1787,2 & 3033,9 & 10.019 \\
\hline
\end{tabular}

Fuente: Elaboración propia a partir de VIII Encuesta de Presupuestos Familiares (EPF) (INE 2018).

El efecto de un IVA diferenciado en el ingreso del hogar no es menor. Suponiendo el escenario de la alternativa 1, cuando el decil I enfrenta una tasa del IVA del 16\%, la carga del impuesto (gasto en IVA como porcentaje del ingreso disponible) para el decil de menores ingresos disminuye en 4,3 puntos porcentuales con respecto al statu quo $(22,9 \%$ vs. $27,2 \%$ ). Por su parte, la carga en los hogares de mayores ingresos (decil X), al enfrentar un IVA del 19,9\%, aumenta en 0,4 puntos porcentuales con respecto al statu quo (9,3\% vs. 8,9\%) (Tabla 2 panel A).

Considerando el escenario de la alternativa 3, donde el aumento en la tasa del IVA es escalonado, cuando el decil I enfrenta una tasa del IVA del $11 \%$, la carga del impuesto disminuye en 11,4 puntos porcentuales con respecto al statu quo (15,8\% vs. $27,2 \%)$, mientras que la carga del impuesto del decil $\mathrm{X}$, al enfrentar una tasa del $21 \%$, aumenta en un punto porcentual con respecto al escenario actual (9,9\% vs. 8,9\%). De esta forma, es evidente que una tasa diferenciada, especialmente una tasa escalonada, beneficiaría en mayor proporción a los hogares más vulnerables.

\footnotetext{
${ }^{15}$ Resulta de dividir el valor del incremento en la tasa del IVA a los deciles VII y VIII (1 pp) y IX y X (2 pp), por la disminución en la tasa del IVA del decil I y II (8 pp). Los cambios correspondientes considerando la reducción en los deciles III y IV (4 pp), son 0,25 y 0,5.
} 
Tabla 2. IVA COMO \% DEL INGRESO DISPONIBLE PROMEDIO

\begin{tabular}{|c|c|c|c|c|c|c|c|c|c|c|}
\hline Decil & I & $\|$ & III & IV & V & VI & VII & VIII & IX & $x$ \\
\hline Panel a & \multicolumn{10}{|c|}{ IVA como $\%$ del ID } \\
\hline Statu quo & $27,2 \%$ & $19,4 \%$ & $17,7 \%$ & $15,8 \%$ & $14,8 \%$ & $13,7 \%$ & $13,1 \%$ & $12,6 \%$ & $11,7 \%$ & $8,9 \%$ \\
\hline Alternativa 1 & $22,9 \%$ & $16,3 \%$ & $14,9 \%$ & $13,3 \%$ & $14,8 \%$ & $13,7 \%$ & $13,7 \%$ & $13,2 \%$ & $12,3 \%$ & $9,3 \%$ \\
\hline Alternativa 2 & $18,6 \%$ & $13,3 \%$ & $12,1 \%$ & $10,8 \%$ & $14,8 \%$ & $13,7 \%$ & $14,3 \%$ & $13,7 \%$ & $12,8 \%$ & $9,8 \%$ \\
\hline Alternativa 3 & $15,8 \%$ & $11,2 \%$ & $14,0 \%$ & $12,5 \%$ & $14,8 \%$ & $13,7 \%$ & $13,8 \%$ & $13,2 \%$ & $12,9 \%$ & $9,9 \%$ \\
\hline Panel b & \multicolumn{10}{|c|}{ Cuociente entre decil ' $\mathrm{j}$ ' $\mathrm{y}$ decil $\mathrm{X}(\mathrm{j}=\mathrm{I}$ al $\mathrm{X}$ ) } \\
\hline Statu quo & 3 & 2,2 & 2 & 1,8 & 1,7 & 1,5 & 1,5 & 1,4 & 1,3 & 1 \\
\hline Alternativa 1 & 2,5 & 1,7 & 1,6 & 1,4 & 1,6 & 1,5 & 1,5 & 1,4 & 1,3 & 1 \\
\hline Alternativa 2 & 1,9 & 1,4 & 1,2 & 1,1 & 1,5 & 1,4 & 1,5 & 1,4 & 1,3 & 1 \\
\hline Alternativa 3 & 1,6 & 1,1 & 1,4 & 1,3 & 1,5 & 1,4 & 1,4 & 1,3 & 1,3 & 1 \\
\hline
\end{tabular}

Fuente: Elaboración propia a partir de VIII Encuesta de Presupuestos Familiares (EPF) (INE 2018).

Si se mide la regresividad como el cuociente entre la carga que representa el IVA para cada decil (deciles del I al IX) y para el decil X (Tabla 2, panel B), se observa que la carga del IVA en los hogares de menores ingresos (decil I) pasa de ser el triple de la carga en el decil X, a 2,5 veces en el caso de la alternativa 1, menos del doble en el caso de la alternativa 2 y 1,6 veces en la alternativa 3; es decir, con una tasa del impuesto específica a cada nivel de ingreso existe una caída significativa en la regresividad del impuesto. Aunque los cambios son mayores en los deciles I y II, también son significativos para los deciles III y IV.

Sin embargo, pese a los potenciales beneficios de la propuesta, es claro que se necesitan métodos especiales para lograr el cobro de tasas diferenciadas. En la siguiente sección se presentan de manera detallada dos métodos capaces de atenuar la regresividad del impuesto, de modo de obtener un IVA menos regresivo como se simuló en esta sección.

\section{Alternativas para alcanzar un IVA progresivo}

El uso de tecnología puede mejorar los sistemas de recaudación tributaria a través de la aplicación de tasas personalizadas, el perfeccionamiento del proceso de cumplimiento en el pago de impuestos, el asesoramiento útil y la mayor transparencia fiscal (Aplin 2019). En el caso específico del IVA, la implementación de desarrollos tecnológicos disponibles podría reducir su regresividad diferenciando a los contribuyentes 
según su nivel de ingresos (Bird y Zolt 2008) y además permitiría disminuir los niveles de evasión (Bellon et al. 2019).

En esta sección se presentan dos alternativas para atenuar la regresividad del impuesto. La primera constituye una solución en el momento del pago — método ex dure - del impuesto, mientras la segunda presenta una solución posterior al pago del mismo -método ex post. Ambas propuestas operarían para todos los bienes y servicios afectos a IVA.

\section{I Método ex dure para reducir la regresividad del IVA}

Una alternativa para la consecución de un IVA menos regresivo yace en el uso de tecnología durante el cobro y pago del impuesto. ${ }^{16}$ Ainsworth (2006a) señala que un IVA más progresivo puede alcanzarse mediante el uso de tres desarrollos tecnológicos: primero, certificados de exención vinculados a datos biométricos e integrados en tarjetas inteligentes de identificación; segundo, regímenes de impuestos completamente digi-

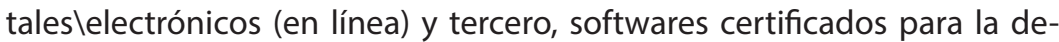
terminación de los impuestos. Básicamente se propone un sistema en el que la facturación, declaración y recaudación de impuestos se realice en tiempo real a través del uso de sistemas informáticos desarrollados por empresas que proporcionen softwares certificados.

El proceso es totalmente digitalizado y consiste en lo siguiente. Una vez que el consumidor acude a un punto de venta minorista debe presentar su tarjeta de identificación. El identificador biométrico en la tarjeta indicaría la tasa a la que cada consumidor estaría afecto. Posteriormente se establece un canal de comunicaciones seguro a través de un chip de comunicaciones en la tarjeta. El chip en la tarjeta de identificación interactúa con el sistema de cobro del minorista a través de una interfaz digital e identifica los bienes y servicios que el consumidor

\footnotetext{
${ }^{16}$ En 2012, Uruguay implementó un programa de reducción del IVA para sectores vulnerables. Este se encuentra focalizado en hogares en extrema vulnerabilidad y beneficiarios del programa Asignaciones Familiares (AFAM). La solución consiste en la exención del impuesto al momento del pago, pero únicamente para las compras pagadas con las tarjetas usadas para la entrega de beneficios (la Tarjeta Uruguay Social o la tarjeta BPS Prestaciones). Estas tarjetas están asociadas a las cuentas electrónicas de los programas sociales donde el gobierno carga mensual o bimestralmente los beneficios de distintos programas sociales (Rastelletti 2021). Más que una solución transversal a la regresividad del IVA, la medida implementada en Uruguay buscaba mejorar los beneficios sociales y promover el uso de medios electrónicos como medio de pago.
} 
puede adquirir con su respectiva tasa. A continuación se explican en mayor detalle los tres componentes tecnológicos necesarios. En un inicio se revisa la experiencia internacional, para después ahondar en el estado de estos desarrollos en el país.

\section{Biometría y tarjetas de identificación}

La biometría consiste en características únicas y medibles de las personas, las cuales son utilizadas para reconocer o verificar una identidad a través de la autentificación o identificación. ${ }^{17}$

Respecto de las tarjetas con identificadores biométricos, o tarjetas inteligentes, existen al menos dos razones por las que su uso va en ascenso. En primer lugar, estos dispositivos ofrecen mayor seguridad, al ser la tarjeta el único lugar en el que existe la plantilla biométrica. En segundo lugar, considerando que la verificación de huellas biométricas se realiza localmente en la tarjeta, no existe limitación en el número de usuarios (Bhardwaj y Swetleena 2018). Lo anterior explica por qué estos dispositivos son una buena alternativa para sistemas de identificación nacional, donde millones de usuarios deben ser identificados.

Diversas experiencias internacionales justifican el uso de tarjetas biométricas. Ejemplo de ello son los países de la Unión Europea, donde desde hace más de una década se han adoptado gradualmente sistemas de pasaportes y tarjetas de identificación biométricos reconocidos en todos los países miembros (Arora 2008). Igualmente, desde 2008 Japón utiliza tarjetas inteligentes para evitar que los menores de edad consuman tabaco (Kanda et al. 2011). Un caso más interesante es el de Malasia, país que cuenta con tarjetas inteligentes multipropósito que funcionan como pasaporte, licencia de conducir y como tarjeta de acceso para beneficios sociales y programas del gobierno (Loo, Yeow y Chong 2009).

\footnotetext{
${ }^{17}$ En el caso de la autentificación o registro, en una primera fase se realiza la recopilación del dato biométrico (iris, huella, rostro), el cual es almacenado en una plantilla biométrica; posteriormente se compara el dato almacenado con el entregado que, en caso de coincidir, da como resultado la verificación de la identidad de la persona. En el caso de la identificación se compara la muestra biométrica con varias plantillas biométricas y, en caso de concordar con alguna de ellas, da como resultado la identificación de una persona (Garrido y Becker 2017). De manera intuitiva, para la autentificación una persona confirma su identidad probando que sus datos biométricos coinciden con los datos correspondientes a su propia persona, los cuales han sido almacenados anteriormente en la plantilla biométrica. En la identificación se comparan los datos de la persona con todas las plantillas biométricas existentes, comprobando de esta manera si los datos están registrados.
} 
En el caso del IVA, el uso de tarjetas con identificadores biométricos permitiría la asociación de una persona a una aplicación personalizada del impuesto al consumo. Para esto las tarjetas de identificación deben contar con chips inteligentes que permitan la identificación de los contribuyentes. Así, cada individuo podría tener derecho a una tasa diferenciada del impuesto al momento de efectuar la compra. En este punto es necesario además la evaluación individual de los derechos de exención (total o parcial), los que deberían ser limitados en términos de cantidad o valor, vale decir, tener un máximo por persona y período para evitar que el beneficio sea transferido a otros por la compra de bienes y servicios por cuenta de terceros (Ainsworth y Akioka 2007).

\section{Regímenes de impuestos digitaleslelectrónicos}

Un segundo desarrollo necesario es la digitalización del impuesto, que puede entenderse como la incorporación de tecnología en el proceso tributario, posibilitando o exigiendo que la declaración y el pago del impuesto se realicen en línea, que los contribuyentes emitan documentación por medios tecnológicos y que los trámites asociados al proceso se realicen por internet (Cerda 2020). Además, la evidencia sugiere que este desarrollo ha permitido mejorar y modernizar la administración tributaria, disminuir los niveles de fraude/evasión y aumentar los niveles de formalidad de la economía. Las experiencias europea, brasilera y peruana constituyen buenos ejemplos en esta materia.

En el continente europeo, los avisos de inicio y finalización de la actividad imponible, así como las declaraciones correspondientes son completamente en línea y pueden hacerse desde cualquiera de los Estados miembros. Asimismo, el continente cuenta con un sistema de facturas digitales. Cada factura contiene la información necesaria para determinar el régimen de IVA aplicable a la transacción, permitiendo a las autoridades llevar a cabo los controles de ejecución y a los compradores, ejercer su derecho a la deducción (Ainsworth 2006a).

Brasil también ha optado por una digitalización del IVA. El país cuenta con facturas electrónicas (Nota Fiscal Electrónica), que son creadas cada vez que se produce un acto imponible. El proceso de emisión de la factura automáticamente pasa una copia a la autoridad fiscal para su aprobación. De esta manera, todas las ventas y compras se presentan 
en tiempo real a la autoridad, permitiendo un mejor control del pago de impuestos y la detección de fraude fiscal (Aplin 2019). Una innovación adicional en algunos estados de Brasil es un pequeño reembolso del IVA emitido a clientes individuales, con el objetivo de incrementar los niveles de formalidad de la economía. Para acceder al beneficio, los consumidores únicamente deben solicitar su comprobante fiscal y dar su identificación. Posteriormente, los comerciantes deben transmitir el registro de comprobantes a la administración tributaria y una vez que el comercio paga el impuesto, el fisco automáticamente entrega una parte del mismo al comprador (González et al. 2011).

Perú también constituye un ejemplo interesante. En dicho país, la adopción de facturas electrónicas fue gradual, debido a los desafíos que representó la reforma tanto en la administración tributaria como para los contribuyentes. Pese a esto, la reforma tuvo efectos positivos en el cumplimiento de las obligaciones tributarias, especialmente en los sectores que padecían de bajo cumplimiento como comercios minoristas (De Velazco 2016). Igual de positiva fue la digitalización del IVA en China. El uso de facturas electrónicas permitió el aumento de los ingresos tributarios a través de la disminución en los niveles de evasión (Fan et al. 2018)

Los ejemplos anteriores muestran la fortaleza de la digitalización, no solo en cuanto a exenciones se refiere, sino en el alcance de otros objetivos como lo son evitar la evasión tributaria y aumentar la formalidad de la economía.

\section{Softwares certificados para la aplicación del IVA}

El tercer desarrollo necesario para reestructurar la aplicación del IVA consiste en establecer un régimen de certificación de software para el programa utilizado en el nivel de venta minorista, con el fin de lograr un manejo ético, seguro y adecuado del sistema y de los datos inmersos en el proceso tributario. Para la certificación es necesaria una extensa verificación de seguridad del software, del desarrollador y del proveedor de servicios (Ainsworth 2006a). Además, el software debe ser capaz de reconocer la tasa reducida o la exención del impuesto y asociarlos correctamente a los bienes y servicios calificados para el tratamiento diferenciado de un usuario específico. Es también necesario que el software calcule el impuesto y retenga un archivo de auditoría por cada transacción (Ainsworth y Akioka 2007). 
Estados Unidos constituye un buen ejemplo en este ámbito. El país emplea softwares certificados en el cálculo y cobro del impuesto al consumo bajo el Acuerdo Simplificado de Impuesto a las Ventas (SSUTA, por su sigla en inglés). ${ }^{18}$ Bajo el SSUTA, tres tipos de certificaciones son posibles. La primera, la certificación de softwares internos desarrollados por los propios contribuyentes; la segunda, la certificación de softwares desarrollados por terceras partes que serán utilizados internamente en el sistema contable de un contribuyente, y la tercera, la certificación de proveedores de servicios, quienes deben garantizar no solo el buen desempeño del software utilizado, sino que además deben probar su capacidad para desarrollar la totalidad de la actividad contable, que incluye declaración de impuestos, transferencias de dinero y otros servicios de cumplimiento tributarios (Ainsworth 2011).

En cuanto a la operatividad de los softwares y siguiendo las recomendaciones de la OECD (2019), la aplicación de buenas prácticas ex post a la certificación, como la evaluación e inspección periódica de los softwares, constituye un requisito necesario para garantizar el buen funcionamiento de los mismos en el largo plazo.

\subsection{Algunas consideraciones}

Aunque el método propuesto puede aliviar la regresividad inherente en el IVA y reducir los niveles de evasión tributaria, varios elementos deben ser considerados para una correcta ejecución de la propuesta. Por ejemplo, definir cómo será la participación de los comercios dentro del nuevo sistema, además de entender las barreras para su adopción, son elementos que deben ser considerados. A continuación se detallan brevemente estos aspectos.

\section{Participación de los comercios}

Ainsworth (2006b) señala que, ante un esquema digitalizado del IVA, los comercios pueden participar de forma voluntaria u obligatoria. Bajo un esquema obligatorio se requiere que todos los comercios que realicen ventas a los consumidores finales cuenten con lectores biométricos, además de asegurar que sus sistemas contables y de determinación de im-

\footnotetext{
${ }^{18}$ Streamlined Sales and Use Tax Agreement.
} 
puestos estén configurados para reconocer los certificados integrados en las identificaciones. Un tercer proveedor podría ofrecer estos servicios a los comercios a un determinado costo, donde una fracción o la totalidad del mismo podría ser asumida por parte del gobierno, especialmente en el caso de comercios pequeños.

Bajo un esquema voluntario, dos enfoques son posibles. Los comercios que no participan pueden estar impedidos de efectuar compras y ventas (total o parcialmente) diferenciadas, es decir, aplicarían la tasa estándar máxima del IVA (aquella aplicable al decil de más altos ingresos). Alternativamente se les puede pedir que mantengan en papel registros auditables de las transacciones, registrando a la persona que realizó la compra, el artículo comprado, junto con el código emitido por el gobierno que asocia a la persona y a la compra; sin embargo, es claro que está opción es ineficiente y que es preferible mudar a la solución digital.

\section{Formalidad de la economía}

Un alto grado de informalidad en la economía podría limitar la efectividad del método propuesto para revertir la regresividad del IVA (Contreras, Cabello y Piñones 2013). Sin embargo, el método propuesto constituye una oportunidad para elevar el grado de formalidad en la economía, lo que alcanzaría de mejor manera el resultado buscado. En efecto, la existencia de tasas diferenciadas podría incentivar a los consumidores de bajos ingresos a exigir que las operaciones se realicen de manera formal. ${ }^{19}$ Esto repercutiría en una mayor formalización a nivel agregado y por ende en un aumento en la recaudación total.

\section{Topes máximos en las compras}

El hecho de que un grupo de hogares esté afecto a una tasa muy inferior a la de otros grupos, podría dar lugar a arbitraje entre personas pobres y no pobres (Agostini 2019). En este punto, una de las acciones necesarias es establecer un tope máximo en el monto que podría ser comprado por una misma persona (hogar) durante un cierto período (mes/trimestre), de manera de evitar vulneraciones en el sistema.

\footnotetext{
${ }^{19}$ El incentivo depende de cómo se reparte entre consumidores y comercio detallista el IVA no declarado -el incentivo es máximo (mínimo) si el comercio (no) cobra el IVA y no emite la respectiva boleta.
} 


\section{Identificación de los beneficiarios}

Uno de los puntos centrales para el funcionamiento de este método es la identificación de los beneficiarios y la clasificación de los mismos según grupos de ingreso, de manera que cada uno de estos quede afecto a una tasa específica. En este sentido es necesario establecer un instrumento confiable que permita la clasificación de los hogares. En el caso de Chile, el Registro Social de Hogares (RSH) es un buen mecanismo. Este es un sistema coordinado por el Ministerio de Desarrollo Social y apoyado por las Subsecretarías de Evaluación Social y de Servicios Sociales, que contiene información socioeconómica autorreportada por los hogares y de bases administrativas, y que permite construir la calificación socioeconómica de un hogar para su clasificación en distintos segmentos o tramos de ingreso. Es importante que este registro esté siempre actualizado (o se actualice periódicamente) y se construya en base a criterios objetivos y técnicamente sólidos. Además, es importante que no presente rigideces que dificulten la reclasificación de los hogares frente a macroshocks. ${ }^{20}$

\section{Barreras a la adopción}

La adopción de un IVA completamente digital podría verse amenazada por distintos factores. Entre los factores que frenarían su adopción se encuentran la posible respuesta reacia al uso de métodos digitales por parte de la población, los costos monetarios y administrativos que implica la digitalización, así como las posibles amenazas a la privacidad individual. Estos se discuten en detalle a continuación.

Exclusión digital: La exclusión digital hace referencia a aquellos usuarios que no quieren o no pueden utilizar métodos digitales para interactuar con el gobierno, a causa de diferencias culturales (asociados usualmente a un problema generacional o etario) en la adopción de tecnologías, creencias (desconfianza) sobre el intercambio de información con el Estado y/o por un problema de costos. En este caso, el Estado debe hacerse cargo de informar y/o educar adecuadamente a los usuarios sobre el nuevo método de administración tributaria, aunque Aplin

\footnotetext{
${ }^{20}$ Un análisis detallado de las deficiencias que pueda presentar el Registro Social de Hogares trasciende el objetivo de este artículo, pero ciertamente es un tema relevante que debe analizarse, en especial a la luz de las dificultades que han tenido las autoridades para llegar con ayudas a las familias durante la crisis sanitaria.
} 
(2019) asegura que ante altos niveles de exclusión lograr un cumplimiento perfecto del nuevo método no es posible. ${ }^{21}$

Costos y complejidad: Para la operatividad de este sistema se necesita una inversión importante en los sistemas de información necesarios (Barreix, Bes y Roca 2012). Los costos de la transición hacia un nuevo método de administración tributaria son inmediatos, mientras que los beneficios de un IVA digital toman tiempo en materializarse (Aplin 2019). En este punto, el desafío será demostrar que cualquier inversión en este sistema será compensada con beneficios en el largo plazo.

Seguridad y privacidad: Otro de los puntos a considerar tiene que ver con la invasión a la privacidad individual. Con un sistema tributario digital los gobiernos pueden recopilar distinta información sobre los individuos y sus hogares (Aplin 2019), por cuanto el sistema registraría cada compra hecha por los usuarios, su precio, el número de cada artículo, el lugar y el tiempo en el que se registró cada compra (Barreix, Bes y Roca 2012). En este punto serán importantes las estrategias que el gobierno pueda utilizar para establecer una mayor confianza con los ciudadanos.

Contar con una base legal adecuada para la recopilación y almacenamiento de información privada digital y su uso (restringido a fines específicos) podría ser una solución factible. Este desafío y cómo lo están enfrentando distintos países es un tema de investigación que por sí solo trasciende el ámbito de este artículo, pues se aplica a muchos otros ámbitos de la vida de los ciudadanos ${ }^{22}$ (geolocalización y contactos estrechos en el caso de la actual pandemia, por ejemplo), pero una solución adecuada es un prerrequisito indispensable para implementar cualquiera de las dos opciones discutidas en este artículo.

\subsection{Factibilidad del método}

En cuanto a la factibilidad de adoptar el método propuesto en el país, la evidencia sugiere que Chile cuenta con experiencia en estos ámbitos, aunque existen tareas pendientes para su plena implementación. A continuación se presentan los avances en cada uno de estos campos.

\footnotetext{
${ }^{21}$ Aunque la ausencia de conectividad puede ser un problema, implícitamente asumimos que esta barrera irá desapareciendo de manera exponencial conforme avancen otras políticas públicas y el país se desarrolle. La actual situación de pandemia y sus efectos (educación y trabajo a distancia) creemos implicará un avance importante en esta materia.

${ }^{22}$ Véase Conde y Hernández (2019).
} 


\section{Tarjetas de identificación con identificadores biométricos}

El uso de información biométrica en Chile cuenta con larga trayectoria, tanto en instituciones públicas como privadas. A partir de 2002, por ejemplo, la Policía de Investigaciones (PDI) incorporó el uso de tecnología biométrica en los controles migratorios, lo que incluyó la adopción de lectores de pasaportes biométricos, autentificadores de documentos de viaje y el uso de equipos de reconocimiento dactilar (Sepúlveda 2008). Asimismo, desde 2010 el sector de salud público (y privado), en particular Fonasa, trabaja con datos biométricos (huella dactilar) para la compra de bonos y para la emisión de licencias médicas electrónicas. Incluso en el sistema bancario el uso de datos dactilares o faciales es común para la verificación de la identidad de una persona.

Específicamente en lo que se refiere a tarjetas de identificación biométricas, los carnés de identidad emitidos desde septiembre de 2013 cuentan con un chip interno de almacenamiento de información personal, que entre otros datos incluye información biométrica como huella dactilar y datos faciales. En este sentido, Chile cuenta con tarjetas de identificación inteligentes que podrían ser utilizadas para la verificación de personas que serían beneficiarias de una posible exención tributaria.

\section{Digitalización tributaria}

En lo que respecta a la digitalización tributaria, el país generó el primer proyecto de facturación electrónica en Latinoamérica (Rodríguez 2015), mismo que facilitó la emisión electrónica de documentos que incluyen facturas, facturas de compra, liquidaciones facturas y notas de débito y crédito, ${ }^{23}$ llegando a ser obligatoria la facturación electrónica a partir de 2018. Asimismo, a partir de mediados de 2020 y en conformidad a la Ley de Modernización Tributaria, el país progresó en cuanto a la emisión de boletas electrónicas al publicar la Resolución Exenta SII N 74, que instruye sobre el procedimiento que deberán seguir los contribuyentes para su emisión y sobre la información que deberán contener estos documentos tributarios, incluyendo el desglose de los impuestos correspondientes.

\footnotetext{
23 Para mayor información revisar la Ley 20721 referente a la legislación tributaria en materia de factura electrónica.
} 
Para la emisión de documentos digitales, los contribuyentes pueden utilizar el sistema de facturación gratuito del Servicio de Impuestos Internos (SII), un sistema de facturación desarrollado por el propio contribuyente o un sistema de facturación adquirido de otros proveedores (SII 2018). Cabe mencionar que en el caso de las facturas y boletas electrónicas los contribuyentes tienen la obligación de desglosar los montos correspondientes al IVA y otros impuestos, permitiendo de esta manera conocer el monto correspondiente a la venta y el monto correspondiente al impuesto.

\section{Certificación de softwares}

Con respecto a la certificación de softwares, los contribuyentes que emiten comprobantes electrónicos deben contar con sistemas aptos para la emisión de estos documentos. En el caso de que los contribuyentes utilicen el sistema de facturación gratuito del SII, no es necesaria una certificación adicional a la que el sistema trae de forma inherente, mientras que en el caso de que los contribuyentes utilicen sistemas propios o sistemas de terceros (proveedores) se requiere una certificación del SII.

Para la certificación del SII, los sistemas desarrollados por los propios contribuyentes o aquellos adquiridos de terceros deben pasar algunas pruebas que garanticen su desempeño. Las pruebas se refieren al envío de documentos, la simulación de documentos, el envío de documentos incluido el timbre electrónico, el envío de información electrónica de ventas y compras, entre otras (Rodríguez 2015). De esta manera, los contribuyentes pueden asegurarse de que todas las transacciones sean realizadas bajo un sistema seguro.

\subsection{Costo del método}

En cuanto al costo estimado de su implementación, Tailandia, India y Hong Kong constituyen ejemplos que dan luces sobre este aspecto. En esos tres casos los proyectos de identificación inteligente requirieron la compra de softwares especializados para la identificación y verificación de los usuarios, de manera que los habitantes pudieran acceder a diferentes beneficios, programas y servicios del Estado de manera segura.

En el caso de Tailandia, cuyas tarjetas de identificación biométrica son utilizadas como cédula de identidad, licencia de conducir y medio 
para recibir otros servicios sociales (seguridad social, salud, entre otros), el gobierno destinó aproximadamente US\$49 millones para el proyecto de identificación inteligente, que implicó la adquisición de softwares especializados para autentificación y verificación, y la producción de 64 millones de tarjetas inteligentes, es decir, menos de un dólar por cada tarjeta de identificación (Gunawong y Gao 2010).

En India, dentro de su objetivo de gobierno digital se incluyó el programa de identificación inteligente multipropósito —Proyecto Aadhaar-, que entre otros fines buscó mejorar la focalización de subsidios. De acuerdo a cifras de la Unidad de Identificación de la India (UIDAI), se estima que entre 2009 y 2015 el gobierno invirtió aproximadamente US\$859 millones en su proyecto de identificación. En total se emitieron 786 millones de credenciales inteligentes, implicando un costo aproximado de US\$1,09 dólares por cada tarjeta biométrica generada.

Un último caso representativo es el de Hong Kong, donde el uso de tecnología biométrica se inició en 2003. A partir de 2018 el territorio autónomo empezó con el proceso de renovación del sistema de identificación inteligente, que incluyó mejoras en cuanto a la seguridad y el registro de los datos biométricos. El nuevo carné de identidad permite a sus usuarios acceder a distintos servicios del Estado, que incluye permisos de migración. Características propias de esta tarjeta hace que su costo sea más elevado que en los dos casos anteriores. ${ }^{24}$ De hecho, el costo estimado del proyecto es de aproximadamente US\$188 millones, para la producción de 8,8 millones de tarjetas en un plazo de cuatro años (Cheng 2017), lo que sugiere un costo de US\$21 por tarjeta.

Con respecto al costo de los lectores de huellas en los que deberían incurrir los comercios, de acuerdo a información provista por la empresa Imed S.A., se estima que el valor de dichos dispositivos ronda entre los US\$60 y los US\$70, de forma que son dispositivos económicamente accesibles para la gran mayoría de los comercios establecidos. Lo anterior no excluye la posibilidad de que, para comercios muy pequeños, se requiera de algún subsidio estatal.

Lo señalado anteriormente demuestra que la implementación de este método intensivo en tecnología es factible y accesible en cuanto a

\footnotetext{
${ }^{24}$ Las nuevas tarjetas de identificación biométricas incluyen ocho funciones que garantizan su seguridad: holograma con onda y efecto 3D, alivio táctil, tinta con propiedades variables, impresión de arco iris, ventana transparente, fondo de varios patrones, imagen láser de retrato, imagen a todo color UV y texto microimpreso (Departamento de Inmigración de Hong Kong 2018).
} 
costos. Chile cuenta con tarjetas de identificación inteligentes, con un sistema de impuestos digitalizado, al menos en lo referente al IVA, y con procesos establecidos para la certificación de softwares.

\subsection{Método ex post para reducir la regresividad del IVA}

Un segundo método consiste en la devolución del IVA pagado con posterioridad a haberse efectuado la compra. Ecuador, Canadá y Colombia son ejemplos de esta alternativa. En el caso de Ecuador, las personas con discapacidad y los adultos mayores tienen derecho a una devolución mensual del IVA pagado en bienes y servicios de primera necesidad. ${ }^{25}$ Para ello, los beneficiarios deben llenar una solicitud a ser entregada de manera virtual o presencial a la institución tributaria en conjunto con las facturas correspondientes. En el caso de ser aprobada la solicitud, la devolución se realiza de manera directa a la cuenta bancaria señalada por el beneficiario. ${ }^{26}$

Igual de sobresaliente es el caso de Canadá. En el país se realizan transferencias trimestrales a las familias de bajos ingresos como compensación al pago del IVA. En este caso, el monto de la transferencia depende del ingreso neto del hogar, el estado civil del jefe de hogar y el número de hijos, mas no del consumo efectivo del hogar. El método de pago es directo. La Agencia Tributaria de Canadá emite el pago a la cuenta del beneficiario previamente inscrita de manera que el proceso es sencillo y célere. ${ }^{27}$

Colombia es uno de los países más recientes en adoptar esta estrategia. Precisamente con el objetivo de alcanzar mayor equidad tributaria, a finales de marzo de 2020 el país inició el proceso de compensación del IVA, consistente en un pago bimestral de $\$ 75.000$ colombianos $^{28}$ para aquellos hogares vulnerables inscritos en el Sistema de Identificación de Potenciales Beneficiarios de Programas Sociales (SISBEN) y que sean be-

\footnotetext{
${ }^{25}$ Se consideran bienes y servicios de primera necesidad las divisiones de vestimenta, vivienda, salud, alimentación, educación, comunicación, cultura, deporte y transporte y movilidad.

${ }^{26}$ Para mayor información revisar Devolución del Impuesto al Valor Agregado en Ecuador. Disponible en: https://www.sri.gob.ec/web/guest/devolucion-impuestos [2 de diciembre 2021].

27 Para mayor información revisar la información de la Agencia Tributaria Canadiense. Disponible en: https://www.canada.ca/en/revenue-agency/services/child-family-benefits/ goods-services-tax-harmonized-sales-tax-gst-hst-credit.html [2 de diciembre 2021].

${ }^{28}$ Equivalente a US\$21,95 según tipo de cambio oficial del Banco Central de Colombia al 17 de diciembre de 2020.
} 
neficiarios de los programas Familias en Acción, Colombia Mayor y Jóvenes en Acción (Cuevas 2020). Al igual que en Ecuador y Canadá, el pago es directo y se realiza mediante los sistemas de transferencias empleados para el pago de otros beneficios sociales. ${ }^{29}$

En esta misma línea, Barreix, Bes y Roca (2012) proponen un 'IVA personalizado' capaz de devolver el pago del IVA a los deciles de menores ingresos. El monto a ser devuelto estaría calculado en base al consumo de un agente representativo de los deciles de menores ingresos, de manera que a todos los hogares de los deciles beneficiarios se les entrega el mismo monto independientemente de su consumo.

Sin embargo, el uso de tecnología permitiría ir más allá de la propuesta de estos autores y de lo implementado en Canadá, Ecuador y Colombia, al permitir que la devolución del IVA sea específica al consumo de cada persona beneficiaria. En detalle, una vez que el consumidor acude a un punto de venta, la transacción que el consumidor realiza queda registrada en el sistema de impuestos. La información de las compras queda almacenada hasta que, después de un tiempo establecido, la devolución del dinero pagado por concepto del IVA es acreditada a una cuenta asociada al consumidor.

Tres aspectos tecnológicos son necesarios para su funcionamiento. Los dos primeros son similares a los vistos en el método anterior: regímenes de impuestos digitaleslen línea y softwares certificados, de manera de registrar información precisa sobre el monto que deberá ser devuelto a cada beneficiario utilizando canales seguros para el envío y almacenamiento de la información. El tercero corresponde a la capacidad de realizar transferencias electrónicas directas desde la institución tributaria encargada (Tesorería General de la República) hasta la cuenta personal del beneficiario.

\section{Regímenes de impuestos digitales y softwares certificados}

Al igual que con la alternativa ex dure, la digitalización del impuesto y la certificación de softwares son desarrollos necesarios. Lo anterior implica la entrega de boletas digitales o electrónicas que permitan tener un registro sobre los montos de IVA pagados por cada contribuyente. Con la emisión de boletas digitales se puede obtener información personaliza-

\footnotetext{
${ }^{29}$ Para mayor información revisar Devolución del IVA en Colombia. Disponible en: https:// devolucioniva.dnp.gov.co/ [2 de diciembre 2021].
} 
da, de modo de determinar la devolución específica a realizarse por cada contribuyente. Además, en lo que respecta a softwares certificados, estos permiten el manejo adecuado del sistema y de los datos inmersos en el proceso tributario, siendo necesaria la verificación del software, el desarrollador y el proveedor de servicios (Ainsworth 2006b).

Ambos desarrollos garantizan que la institución tributaria lleve el registro de los montos pagados por concepto del IVA, pero además garantizan que el proceso de envío y almacenamiento de la información se realice en entornos seguros.

\section{Transferencias digitales directas}

La digitalización financiera ha permitido a los gobiernos de distintos países modernizar la forma en la que se entregan las transferencias, bonos o subsidios. Justamente, la implementación de pagos digitales ha conseguido que la entrega de programas públicos sea más eficiente, segura y transparente, además de promover la inclusión financiera de la población (Rutkowski et al. 2020).

De esta manera, en los últimos años los depósitos en cuentas vista o de ahorro a nombre del beneficiario se han vuelto usuales en la entrega de beneficios sociales, aumentando incluso el acceso de personas de bajos ingresos en el sistema financiero. Por lo tanto, la devolución del IVA puede ser realizada de manera digital desde la institución tributaria a la cuenta bancaria del beneficiario, donde el único requisito es contar con una cuenta bancaria y con el registro de la misma en el sistema para el depósito de la devolución del IVA.

\subsection{Algunas consideraciones}

Existen algunos aspectos que deben ser considerados para la aplicación del método anteriormente detallado.

\section{Topes máximos en el monto de la asignación y tiempo de devolución}

Al igual que con el método anterior, es claro que una devolución del IVA a la población más vulnerable puede dar lugar a arbitraje entre personas pobres y no pobres (Agostini 2019). Por lo tanto, para evitar posibles transgresiones es necesario establecer un tope máximo en el monto de la devolución, el que podría ser calculado en base al consumo observado en cada grupo de la población beneficiaria anterior a la reforma. 
Asimismo, establecer el período en el que se realizará la devolución es importante y en este aspecto los casos de Ecuador y Canadá evidencian que es posible establecer períodos de devolución cortos que oscilan entre uno y tres meses.

\section{Elección de los beneficiarios}

La selección de la población beneficiaria es un paso clave. En este aspecto, un recurso útil es el Registro Social de Hogares que, como se mencionó anteriormente, es un sistema de información autorreportada y de bases administrativas que permite construir la calificación socioeconómica de un hogar para su clasificación en distintos segmentos o tramos. Con este instrumento es posible la identificación de los hogares que deberían ser sujetos de la devolución del IVA.

Asimismo, y como se mencionó anteriormente, una buena práctica constituye la actualización permanente del Registro Social de Hogares, de manera de garantizar que la devolución del impuesto esté bien focalizada.

\section{Barreras en la adopción}

La devolución del IVA a un grupo determinado de beneficiarios podría verse amenazada por distintos factores. Entre los factores que frenarían su adopción se encuentran la exclusión financiera y posibles amenazas a la privacidad individual. Estos se discuten en detalle a continuación.

Exclusión financiera: Al ser el método propuesto uno en el que la devolución del IVA es digital y se acredita de manera directa a una cuenta bancaria, un aspecto a considerar es el acceso a servicios financieros que tienen los posibles beneficiarios. En caso de existir un alto porcentaje de personas sin una cuenta bancaria, por ejemplo, se debe fomentar el diseño de productos que se adapten a la población objetivo, como cuentas de bajo costo, sin cobro por mantenimiento o transacciones (Maldonado et al. 2011). Las cuentas RUT ${ }^{30}$ de BancoEstado son una solución ya probada en el país que solo necesita aumentar su cobertura hacia los segmentos aún no bancarizados.

Seguridad y privacidad: similar a lo observado con el método anterior, con la digitalización del impuesto los gobiernos pueden recopilar distinta información sobre los individuos (Aplin 2019), razón por la cual

${ }^{30}$ La cuenta RUT es una cuenta de depósito a la vista con servicios conexos de débito y cajero automático. Una de las características distintivas del producto es que el número de cuenta coincide con el RUT del cliente (número de identificación). 
es necesario contar con un marco legal adecuado que garantice el buen uso de la información recopilada a lo largo del proceso tributario.

\subsection{Factibilidad del método}

Como se explicó anteriormente, el país cuenta con experiencia desde hace ya varios años en lo que respecta a digitalización del impuesto y a la certificación de softwares. Pese a ello, es importante analizar la experticia del país en cuanto a transferencias digitales.

La evidencia señala que Chile cuenta con una serie de programas en los que el pago de algunas transferencias sociales se realiza de forma digital. Muestra de ello son los últimos beneficios otorgados en razón de la crisis sanitaria, como el Bono Covid-19 o el Aporte Fiscal para la Clase Media, que fueron transferidos desde la institución encargada hacia la cuenta personal de cada beneficiario (Rutkowski et al. 2020), resultando en un célere proceso de pago.

Cabe mencionar que uno de los factores que ha posibilitado la entrega de transferencias sociales en el país es la evolución en la tenencia de cuentas bancarias. La cobertura actual de la Cuenta RUT de BancoEstado, cuyas facilidades en cuanto al proceso de solicitud (presencial y online), requisitos (carnet de identidad vigente) y costos (no tiene costos de mantenimiento) han permitido que aproximadamente 11 millones de personas, entre nacionales y extranjeros, cuenten con este instrumento en la actualidad, es un buen punto de partida (Gaete 2020).

\subsection{Costo del método}

En cuanto al costo de la propuesta, al ser un método menos intensivo en tecnología, y considerando que es posible aprovechar los avances en cuanto a bancarización (cuenta RUT), debiese resultar más barato, pues se evita la inversión en dispositivos identificadores del contribuyente basados en biometría (lectores de huella). ${ }^{31}$ De esta manera, una vez que el monto de la devolución es calculado, solo basta efectuar la transferencia

\footnotetext{
${ }^{31}$ El método expost es menos costoso que el método ex dure, ya que no incluye herramientas biométricas para la identificación de los beneficiarios. El no incluir este tipo de tecnología puede implicar un mal uso de los beneficios, al dar espacio para el gasto en consumo de personas que no califican para la devolución del impuesto se haga bajo el RUT de personas que sí califican (suplantación), lo que implicaría que se les devuelva IVA pagado por otros. Sin embargo, estos casos son limitados, al existir un tope máximo para el beneficio.
} 
desde la institución encargada hacia la cuenta asociada al beneficiario. Por lo tanto, la alternativa de una compensación ex post al pago del IVA resulta en una opción más accesible en comparación con la solución ex dure.

Finalmente, es necesario enfatizar que al ser dos métodos que implican el traspaso de información personal, un prerrequisito será establecer un marco legal que garantice la protección de datos y el correcto tratamiento y uso de los datos biométricos, de manera que se disminuya el riesgo de divulgación de la información privada o usos secundarios de la misma (Garrido y Becker 2017).

\section{Conclusiones}

Los avances tecnológicos actuales constituyen una oportunidad para la modernización de los sistemas tributarios. A lo largo de este documento se ha mencionado que la tecnología puede mejorar los problemas asociados a algunos impuestos. En el caso específico del IVA, la tecnología permitiría lograr un menor grado de regresividad del impuesto, pero además sería capaz de mejorar los niveles de cumplimiento a través de una disminución de la evasión.

Dos métodos son posibles para alcanzar un IVA menos regresivo. El primero consiste en una solución ex dure al pago del impuesto, donde la tasa del gravamen sería específica al nivel de ingreso de los hogares. Para ello son necesarios tres desarrollos tecnológicos; el primero, certificados de tasas de gravamen diferenciadas según nivel de ingresos, vinculados a datos socioeconómicos y biométricos. Estos certificados deben estar integrados en tarjetas de identificación inteligentes. El segundo, impuestos completamente digitales\electrónicos; y el tercero, softwares certificados para la determinación y cobro de los impuestos.

El segundo método consiste en una solución ex post al pago del impuesto. En este caso se propone atenuar la regresividad del IVA a través de la devolución total o parcial a algunos grupos, del pago incurrido por dicho concepto. En este caso, además de la digitalización del impuesto y de softwares certificados, es necesario contar con sistemas que permitan realizar transferencias digitales masivas.

Finalmente, dado que los estragos de la crisis sanitaria, junto con las medidas adoptadas para hacer frente a los impactos negativos de la misma, demandarán en el mediano plazo un esfuerzo fiscal que muy probablemente implique un aumento de impuestos para solventar las 
necesidades de financiamiento del Estado, el uso de tecnología permitiría minimizar el problema de regresividad en el caso de una reforma en dicha dirección que comprenda un alza a la tasa del IVA. En este punto los avances en modernización tributaria que ha tenido el país avalan la factibilidad de alcanzar un IVA más progresivo a través del uso de tecnología.

\section{Bibliografía}

Agostini, C. 2019. Devolver el IVA a quienes ganan menos de $\$ 400$ mil: el análisis de expertos a la propuesta del ex Presidente Lagos. Emol, 3 de diciembre. Disponible en: https://www.emol.com/noticias/Economia/2019/12/03/969083/ Analisis-propuesta-Lagos-devolver-IVA.html [2 diciembre 2021].

Ainsworth, R. 2006a. Biometrics: Solving the Regressivity of VATS and RSTS with 'Smart Card'Technology. Boston University School of Law, Working Paper 06-20.

Ainsworth, R. 2006b. Digital Consumption Tax (D-CT). Boston University School of Law, Working Paper 06-26.

Ainsworth, R. 2011. Technology Solves MTIC-VLN, RTvat, D-VAT Certification. Boston University School of Law, Working Paper 11-07.

Ainsworth, R. y Akioka, H. 2007. A Proposal for the Tax Commission: Biometrics and Certified Software for the Consumption Tax. Kansai University Review of Economics 9, 73-109.

Aplin, P. 2019. Digitalization of Tax: International Perspectives. Disponible en: https:// www.icaew.com/-/media/corporate/files/technical/technology/thoughtleadership/digital-tax.ashx [2 de diciembre 2021].

Arora, S. 2008. National e-ID Card Schemes: A European Overview. Information Security Technical Report 13(2), 46-53.

Banco Central de Chile 2020. Informe de Política Monetaria. Junio, Santiago de Chile.

Barreix, A., Bes, M. y Roca, J. 2012. Solving the Impossible Trinity of Consumption Taxes Personalized VAT. Inter-American Development Bank. Disponible en https://www. semanticscholar.org/paper/Solving-the-Impossible-Trinity-of-ConsumptionTaxes-Barreix-Bes/554894144e91c06979703ecda00c797791e46f8d [2 de diciembre2021].

Bennet, H. 2020. Hablando de impuestos personales. Diario Financiero, 21 de abril. Disponible en https://www.df.cl/noticias/opinion/columnistas/hablando-deimpuestos-personales/2020-04-20/184122.html [22 de diciembre 2021].

Bellon, M., Chang, J., Dabla, E., Khalid, S., Frederico, L., Rojas, E. y Villena, P. 2019. Digitalization to Improve Tax Compliance: Evidence from VAT e-Invoicing in Peru. International Monetary Fund.

Bhardwaj, R. y Swetleena, P. 2018. Match-on-Card Biometric Framework. Patiala: Thapar Institute of Engineering and Technology.

Bird, R. y Zolt, E. 2008. Technology and Taxation in Developing Countries: From Hand to Mouse. National Tax Journal 61(4), 791-821.

Cerda, F. 2020. Digitalización de las obligaciones tributarias en Chile. Revista de Estudios Tributarios 23, 153-199.

Cerda, R., González, H. y Larraín, F. 2020. Un plan de recuperación económica para Chile. Santiago: Clapes UC. Disponible en https://www.clapesuc.cl/informe-unplan-de-recuperacion-economica-para-chile [2 de diciembre 2021]. 
Cheng, K. 2017. New Hong Kong Identity Cards Unveiled after 2 Years; Replacements begin Q4 2018. The Hong Kong Press, November 17. Disponible en: https:// hongkongfp.com/2017/11/29/new-smart-hong-kong-identity-cards-unveiled-2years-replacements-begin-q4-2018/ [2 de diciembre 2021].

Conde, B. y Hernández, L. 2019. Evaluación del proyecto de ley que regula la protección y el tratamiento de los datos personales en Chile. Santiago: Clapes UC, Documento de Trabajo 65. Disponible en: https://clapesuc.cl/investigacion/ doc-trabajo-no-65-evaluacion-del-proyecto-de-ley-que-regula-la-proteccion-yel-tratamiento-de-los-datos-personales-en-chile [2 de diciembre 2021].

Contreras, F., Cabello, X. y Piñones, M. 2013. Estado e impuestos indirectos en Chile: Análisis del periodo 2000-2011. Revista Científica Visión del Futuro 18, 76-95.

Cuevas, P. 2020. Cómo lograr que el IVA afecte menos a las personas más vulnerables. Diario Financiero, 1 de diciembre. Disponible en: https://www.df.cl/noticias/ periodismo-de-soluciones/como-lograr-que-el-iva-afecte-menos-a-laspersonas-mas-vulnerables/2020-11-30/192717.html [2 de diciembre 2021].

Departamento de Inmigración de Hong Kong Kong 2018. Hong Kong Identity Cards. Disponible en https://www.sri.gob.ec/web/guest/devolucion-impuestos [2 de diciembre 2021].

De Velazco, J. 2016. La facturación electrónica en el Perú. Lidera 11, 4-10.

Dipres 2018. Estadísticas de las finanzas públicas 2008-2017. Santiago, Chile.

Dipres 2020. Informe de finanzas públicas: segundo trimestre 2020. Santiago, Chile.

Dipres 2021. Informe de finanzas públicas: primer trimestre 2021. Santiago, Chile.

Engel, E., Galetovic, A. y Raddatz, C. 1997. Impuestos y distribución del ingreso en Chile. ¿Es regresivo el IVA? American Economic Review. Disponible en: https://www. researchgate.net/profile/Eduardo-Engel-3/publication/46548403_Impuestos_y_ distribucion_del_ingreso_en_Chile_Un_poco_de_aritmetica_redistributiva_ desagradable/links/577f03a808ae69ab8820f41b/Impuestos-y-distribucion-delingreso-en-Chile-Un-poco-de-aritmetica-redistributiva-desagradable.pdf [2 de diciembre 2021].

Fan, H., Liu, Y., Qian, N. y Wen, J. 2018. The Dynamic Effects of Computerized VAT Invoices on Chinese Manufacturing Firms. CEPR, Discussion Paper 12786.

Gaete, R. 2020. Caracterización de la inclusión financiera en Chile a nivel comunal. Tesis Mg, Universidad de Chile. Disponible en: https://repositorio.uchile.cl/ handle/2250/176676 [2 de diciembre 2021].

Garrido, R. y Becker, S. 2017. La biometría en Chile y sus riesgos. Revista Chilena de Derecho y Tecnología 6, 67-69.

González, G., Montero, M., Olmos, L. y Peláez, F. 2011. Un diseño de IVA personalizado. Focalización de beneficios fiscales de acuerdo a la capacidad contributiva. Montevideo. Disponible en: https://www.dgi.gub.uy/wdgi/afiledownload?2,4,84 4,O,S,0,21822\%3BS\%3B4\%3B108 [2 de diciembre 2021].

Gunawong, P. y Gao, P. 2010. Understanding Government Failure: An Actor-Network Analysis of Thailand's Smart ID Card Project. PACIS, 773.

Instituto Nacional de Estadísticas (INE) 2018. VIII Encuesta de Presupuestos Familiares (EPF). Disponible en: https://www.ine.cl/estadisticas/sociales/ingresos-y-gastos/ encuesta-de-presupuestos-familiares [22 de diciembre 2021].

International Monetary Fund (IMF) 2018. Tax Policy Assessment Framework. Disponible en: https://www.imf.org/external/np/fad/tpaf/tpaf_home.htm [2 de diciembre 2021].

Irarrázaval, G. 2018. Encuesta de presupuestos familiares: disminuye la brecha de ingresos y gastos entre quintiles. Disponible en https://lyd.org/centro-deprensa/noticias/2018/06/encuesta-de-presupuestos-familiares-disminuye-labrecha-de-ingresos-y-gastos-entre-quintiles/ [2 de diciembre 2021]. 
James, K. 2015. The Rise of the Value-Added Tax. Cambridge: Cambridge University Press.

Jorrat, M. 2020. Entrevista por Lina Castañeda. Jorratt: Bajar evasión recaudaría más que bajar impuestos, eliminar franquicias o gravar el patrimonio de altos ingresos. El Mercurio, 15 de septiembre. Disponible en https://portal.nexnews.cl/ showN?valor=ep7t2 [2 de diciembre 2021].

Kanda, H., Osaki, Y., Ohida, T., Kaneita, Y. y Munezawa, T. 2011. Age Verification Cards Fail to Fully Prevent Minors from Accessing Tobacco Products. Tobacco Control 20(2), 163-165.

Loo, W., Yeow, P. y Chong, S. 2009. User Acceptance of Malaysian Government Multipurpose Smartcard Applications. Government Information Quarterly 26(2), 358-367.

Maldonado, J., Moreno, R., Pérez, I. y Barrera, C. 2011. Los programas de transferencias condicionadas: ¿hacia la inclusión financiera de los pobres en América Latina? Disponible en: http://repositorioproyectocapital.com/wp-content/ uploads/2018/02/libro-programas-transferencias-condicionadas-inclusionfinanciera-pobres-2011.pdf [2 de diciembre 2021].

OECD 2020. Consumption Tax Trends 2020: VAT/GST and Excise Rates, Trends and Policy Issues. Disponible en: https://read.oecd.org/10.1787/152def2d-en?format=html [2 de diciembre 2021].

Organisation for Economic Co-operation and Development (OECD) 2019. Roles and Responsibilities of Actors: Governance of Digital Security in Organizations and Security of Digital Technologies. Disponible en: https://www.oecd.org/digital/ global-forum-digital-security/events/2018/ [2 de diciembre 2021].

Rastelletti, A. 2021. IVA personalizado: experiencia de cinco países y su importancia estratégica para la política y la administración tributaria. Disponible en: https:// blogs.iadb.org/gestion-fiscal/es/iva-personalizado-experiencia-latinoamericanay-su-importancia-para-las-administraciones-tributarias/ [2 de diciembre 2021].

Rodríguez, J. 2015. La facturación electrónica vs. control fiscal: análisis comparado con las administraciones tributarias de Chile y España. Tesis Mg, Universidad Andina Simón Bolívar, Quito.

Rutkowski, M., García, A., Bull, G., Guermazi, B. y Grown, C. 2020. Responding to Crisis with Digital Payments for Social Protection: Short-term Measures with Longterm Benefits. Disponible en: https://blogs.worldbank.org/voices/respondingcrisis-digital-payments-social-protection-short-term-measures-long-termbenefits [2 de diciembre 2021].

Sepúlveda, R. 2008. Tecnología aplicada al control migratorio aeroportuario. Santiago, Chile. Disponible en: https://anepe.cl/wp-content/uploads/2020/10/LIBROANEPE-43.pdf [2 de diciembre 2021].

Servicio de Impuestos Internos (SII) 2016. Impuestos indirectos. Santiago, Chile. Disponible en: https://www.sii.cl/ayudas/aprenda_sobre/3072-.html [2 de diciembre 2021].

Servicio de Impuesto Internos 2018. Serie de evasión en el IVA empalmada 2003-2018. Santiago, Chile. Disponible en: https://www.sii.cl/estadisticas/evasion_IVA_ empalmada_2003_2018.pdf [2 de diciembre 2021].

Tax Policy Center 2018. A Citizen's Guide to the Fascinating Elements of the Federal Tax System. Disponible en: https://www.taxpolicycenter.org/briefing-book [2 de diciembre 2021].

Worldwide Tax Summaries 2019. Value-added tax (VAT) rates. Disponible en: https:// taxsummaries.pwc.com/quick-charts/value-added-tax-vat-rates [22 de diciembre 2021]. 


\section{Anexo. Bienes y servicios exentos de IVA}

Para el cálculo de la recaudación posible según cada escenario presentado, se omiten los bienes y servicios exentos del impuesto al valor agregado. A continuación se detallan de manera breve todos los productos que fueron excluidos del análisis en base al Decreto Ley № 825 sobre Impuestos a las Ventas y Servicios.

\section{Salud}

En la división de salud, respecto de las prestaciones médicas efectuadas en clínicas, hospitales, laboratorios y otros establecimientos análogos particulares, cabe señalar que se encuentran expresamente gravadas con el impuesto al valor agregado. Sin embargo, según lo dispuesto en el artículo $13^{\circ}$, dichas prestaciones se encuentran exentas del tributo cuando son efectuadas por personas naturales o jurídicas que en virtud de un contrato o una autorización sustituyan al Fondo Nacional de Salud y a los Servicios de Salud, en la prestación de los beneficios establecidos por ley.

Por lo tanto, las prestaciones médicas efectuadas por clínicas, hospitales, laboratorios y otros establecimientos análogos públicos quedan exentos del impuesto y no son considerados en el análisis.

\section{Educación}

Con respecto a la división de educación, los establecimientos que gozan de exenciones corresponden al sistema estatal, las escuelas, colegios, academias e institutos particulares y la educación profesional técnica y vocacional; se incluyen aquí establecimientos de enseñanzas profesionalizantes como establecimientos de modas, corte y confección, entre otros.

Los ingresos de los establecimientos educacionales que están exentos del IVA corresponden a aquellos derivados de la actividad docente como los ingresos por concepto de matrícula y arancel de escolaridad, además de cursos, seminarios y charlas efectuados en dependencias del establecimiento. Incluye la emisión de certificados de estudios y de alumno regular que pueda realizar el establecimiento, así como la entrega de material pedagógico cuando su valor se encuentre incluido en el importe de la matrícula cobrada por el establecimiento educacional. 
Todos estos servicios no están afectos a IVA, por lo que los pagadores finales de estos no pagan ese impuesto, el que tampoco es retenido por la institución educativa.

\section{Transporte}

En la división de transporte, todos los servicios relacionados con la actividad del transporte de pasajeros se encuentran exentos del IVA al ser una de las actividades clasificadas dentro de las categorías de la Ley sobre Impuesto a la Renta.

\section{Alojamiento, agua, electricidad, gas y otros combustibles}

En base a lo señalado en la Ley, el arrendamiento de bienes inmuebles está exento de IVA, pero en caso de estar amoblados o contar con instalaciones se debe aplicar el impuesto mencionado. Por lo anterior, se excluye el alquiler de bienes inmuebles del cálculo. EP 